\title{
Model of Learning Organizational Development of Primary School Network under the Office of Basic Education Commission
}

\author{
Wipa Sai-rat ${ }^{1}$, Kowat Tesaputa ${ }^{2} \&$ Anan Sriampai ${ }^{2}$ \\ ${ }^{1}$ Major Education Administration and Development, Mahasarakham University, Thailand \\ ${ }^{2}$ Faculty of Education, Mahasarakam University, Thailand \\ Correspondence: Wipa Sai-rat, Major Educational Administration and Development, Mahasarakham University, \\ Thailand. Tel: 66-087-2170181. E-mail: Vipha2517@hotmail.com
}

Received: January 23, 2015 Accepted: March 6, 2015 Online Published: June 29, 2015

doi:10.5539/ies.v8n7p218 URL: http://dx.doi.org/10.5539/ies.v8n7p218

\begin{abstract}
The objectives of this study were 1) to study the current state of and problems with the Learning Organization of the Primary School Network, 2) to develop a Learning Organization Model for the Primary School Network, and 3 ) to study the findings of analyses conducted using the developed Learning Organization Model to determine how to develop the Primary School Network. The research procedure, including the research development, consisted of 3 phases. A descriptive analysis was employed in which percentage, mean, and standard deviation data were used as statistical tools. The research findings revealed the following: 1) The current state of the Learning Organization of the Primary School Network and its associated problems were at moderate and high levels, respectively. 2) The Learning Organization Model for the Primary School involved personnel development of schools in the network that were motivated to engage in continuing development, which led to knowledge, knowledge accumulation, and knowledge formation through work experiences at the individual, team network, and network levels. 3) The implementation of the Learning Organizational Model led to the Primary School Network receiving higher scores on post-development tests compared with pre-development tests and provided satisfaction at the highest level.

In conclusion, the developed model demonstrated usefulness, feasibility, propriety, and accuracy, indicating that it is adequate for implementation in real situations. Furthermore, it was appropriate in the studied context and could be used to develop the Primary School Network into a Learning Network. The knowledge and skills developed during this process can be used to develop the Primary School Network more efficiently.
\end{abstract}

Keywords: learning organization, model, school network, quality, educational development, knowledge

\section{Introduction}

The Educational Institution was the most important organization in providing the Basic Education. In addition, The Education had to be organized for developing the persons to compete with the other countries. The persons needed to be developed in sufficient and appropriate knowledge, competency, and skill with technological progress. Since the new age of Education was required the changes in Learning Style. The students would become center of learning as well as construct their own Learning Model. Therefore, the administrators, teachers, community, and Thai People had to search for modern knowledge throughout the time. Consequently, the Basic School had to be adjusted into Learning Organization. (The Office of Basic Education Commission, 2011, p. 11) The Basic Schools received policy in adjusting people to be Learning Persons in order to construct the Learning Organization to be occurred.

For school implementation, the teachers as well as school administrators were the most important persons. Specifically, the teachers, because they had responsible for Knowledge Management directly. As a result, it was very necessary of these persons to develop their own potentiality to keep pace with the changes ad advancement of the world. In development, in addition to the teachers, the other related persons such as school administrators, school boards, parents, and community had to collaborate in developing the school to be congruent with the occurred changes in a systematic way. The adjustment had to be performed in every parts including one's attitude, value, and basic belief of members in order to determine framework of changes to be relevant to the structure, process, strategy, person's potentiality, organizational culture. Moreover, the alternatives and potential of 
organization had to be developed in order to improve the efficiency (Sangsook, 2005, p. 11).

The basic approach for developing the Learning Organization of Senge (1990, p. 55) who proposed that the Organization to be developed into Learning Organization consisted of 5 factors as follows: 1) Personal Mastery, 2) Mental Models, (3 Shared Vision, 4) Team Learning, and (5 Systems Thinking. The Learning Organization was the organization including the climate in stimulating the learning for person and group to be quickly occurred by using the process of thinking and critiquing in order to understand what was happened. The dynamic learning was based on learning, administration and management, and using the knowledge as an instrument for success in aligned with modern technology. )Marquardt \& Reynolde, 1994) The Office of Basic Education Commission specified the school administration and management by classifying into the Educational Service Area so that the implementation would be more efficient. In the administration and management, the Collaborative Networks were important alternatives as the Hubs of community and School Center in order to develop the students' quality further. It was also an alternative for the administrators to develop quality and efficiency for Educational Management in Primary School of Thailand (Ministry of Education, 2003, p. 6).

The School Network Group 2, Nakhu District, was established according to the announcement of Network Group Establishment in The Office of Kalasin Primary Educational Service Area 3, 2004, and the Revised Issue (the $2^{\text {nd }}$ Issue) 2004 for developing the Educational Quality Management by combining the schools in nearby area into Network Group for cooperating in Quality and Potentiality Development for Educational Management. The building of network collaboration was based on Understanding in objective of collaborative working, assigned working, knowledge and experience sharing. The role of cooperation would be expanded from Educational Cooperation to Cooperating in building the strength in other aspects. Specifically, the Basic School should provide the person group or work unit/organization with willingness for participating in activities as a Cooperative Network under rationale of decentralization, and juridical person. The school administrators were Educational Leaders of schools so that the schools would provide Educational Management appropriately, quickly, completely, and tidily with quality as well as efficiency based on intention of Educational Reform (Doolayakasem \& Ngamwiriyapong, 1997, p. 3).

According to the collection of background and significance of the problem as the above, the researcher viewed the approach of Learning Organization which was being interested in and applied in the Organization in the present as the school service. In addition, there was no completeness in quality of administration and management, and Educational Management. Recently, the Learning Organization in schools of Network School Group 2, Nakhu District, had no direction or precision in Model for developing the Learning Organization. Each school implemented according to its own potentiality. So, it was necessary to provide school development into Learning Organization emergently. The building in cooperation of network was another alternative for obtaining the Learning Organization. In addition, it was also found that there were no research studies of Learning Organization of school network. So, it was very important to conduct research studies in order to find the answer precisely. The researcher as a school administrator of basic School, under jurisdiction of The Office of Kalasin Primary Educational Service Area 3, was interested in conducting research in "Model for developing the Learning Organization on Primary School Network, under The Office of Basic Education Commission." Since the researcher believed that of the school network consisted of Model for developing the school network into Learning Organization with appropriate and precise network, it would cause the Educational Quality Development to be standardized.

\section{Objectives}

1) To study the current situation and the problem of Learning Organization of Primary School Network, under the jurisdiction of The Office of Basic Education Commission.

2) To study the Learning Organization Model of Primary School Network, under the jurisdiction of The Office of Basic Education Commission.

3) To study the findings of the using in the developed Learning Organization Model in order to develop Primary School Network, under the jurisdiction of The Office of Basic Education Commission.

\section{Research Methodology}

For research methodology, the Research and Development was administered. The research area and key informants of this study were the School Group Network 2, Nakhu District, under jurisdiction of The Office of Kalasin Primary Educational Service Area 3 including 121 target groups. There were 2 kinds of research instruments including: 1) the instrument for work implementation was the Implementation Handbook, and 2) the instruments for data collection including (1) the Questionnaire, (2) the Semi-structured Interview, (3) the 
Activity Performance Record, (4) the Knowledge Test, and (5) the Evaluation Form of Satisfaction in Development of Learning Organization Model in Primary School Network under jurisdiction of The Office of Basic Education Commission. The statistic using for data analysis consisted of the Percentage, Mean, and Standard Deviation. There were 3 Phases of research implementation.

Phase 1: was the study of current situation and problem of Learning Organization in Primary School Network under jurisdiction of The Office of Basic Education Commission. The researcher determined 3 sub-steps. Step 1: the document, approach, and related theories with Learning Organization were studied. Step 2: the conceptual framework was determined, and the Questionnaire in framework of research was outlined. Step 3: the current situation and problem of Learning Organization in Primary School Network, was studied.

Phase 2: was the development of Learning Organization Model in Primary School Network under jurisdiction of The Office of Basic Education Commission. The researcher specified 3 sub-steps. Step 1: the Quality School Network was studied. Step 2: the tentative model was outlined. The Handbook for Learning Organization of Primary School Network was established. Step 3: the Quality, Propriety, and Feasibility of Learning Organization Model in Primary School Network were investigated and presented the advisor and experts for considering the Propriety, and Feasibility in practice, the congruency in practice, and the utility of implemental plan, and Learning Organization Model in Primary School Network. In the meanwhile, 5 steps of implementation activity plan were determined as follows: 1) the development of awareness, 2) the activity plan establishment, 3) the development implementation, 4) the sharing, and 5) the evaluation and conclusion.

Phase 3: was the study of findings in usage of developed Learning Organization Model in Primary School Network under jurisdiction of The Office of Basic Education Commission. The researcher determined the implementation into 2 steps as follows : Step 1 ; the Model in Learning Organization in Primary School Network under jurisdiction of The Office of Basic Education Commission, was applied in order to find the efficiency of Learning Organization Model by implementing with 1 network of Primary Schools, under jurisdiction of The Office of Basic Education Commission. Step 2 ; the findings in using the Learning Organization Model Organization in Primary School Network under jurisdiction of The Office of Basic Education Commission, were studied.

\section{Research Instruments}

There were 2 kinds of research instruments including:

1) The instrument for work development was the Implementation Handbook;

2) The instruments for data collection, were (1) the Model Efficiency Evaluation Form, (2) the Satisfaction Questionnaire, (3) the Activity Performance Record, (4) The Interview of Participation in using the Learning Organization Model of Primary School Network.

Research Findings:

1) The research findings of current situation and problem of Learning

Organization of Primary School Network, under jurisdiction of The Office of Basic Education Commission, were as follows:

a. The overall of current situation, was in "Moderate" level. Considering each aspect, found that the implementation was in "Low" level in 2 aspects including the Shared Vision and the Systematic Thinking, and in "Moderate" level for 6 aspects including: the Structure of School Network, the Model in School, the Teachers' Team Learning, the Best Practice Member, the Climate and Organization of School Network, and the Motivation and Morale Development.

b. The problem of Learning Organization in Primary School Network, in overall, was in "High" level. Considering each factor, the problems were ranked in order from high to low as follows: the Systematic Thinking, the Shared Vision, the Teachers' Team Learning, the Best Practice Member, the Climate and Culture of School Network.

2) The findings of developed Model and Handbook Establishment in using the Model for developing the Learning Organization of Primary School Network under jurisdiction of The Office of Basic Education Commission, were as follows:

a. The findings of developed Model and Handbook Establishment in using the Model for developing the Learning Organization of Primary School Network under jurisdiction of The Office of Basic Education Commission, the duration of development was 180 hours or approximately 5 weeks. Various Model and Method were administered in order to develop one's intensive knowledge, comprehension, and learning skill so that the 
participants would be able to use it for Continuous Self Development further. Various techniques being used for developing the Model were as follows: 1) the Training, 2) the Self Study, 3) the Field Trip Study, and 4) the Real Practice including the following details:

- The aspect of Learning Organization in Primary School Network, consisted of 8 aspects consisted of 3 Phases including 3 Phases: Phase 1; the Preparation, Phase 2; the Development Implementation, including 3 activities including Step 1, the readiness preparation in Learning Organization of Network, consisted of 3 activities. Step 2: the development of Learning Organization Model of the Network, consisted of 12 activities, and Step 3, the Stepping into Success in Learning Organization of Network, and Phase 3, the Evaluation,

- The step of Learning into Practice consisted of Step 1; Creation of Wisdom (person level), Step 2; the Practice (team in network level), and Step 3; the Performance Measurement (network level).

- The Guidelines for Implementation consisted of 11 activities including: 4) the outcome of Model consisted of 11 items: the evaluation of possibility of Learning Organization, 2) the Conference for promoting the Knowledge and Comprehension in Learning Organization of Primary School Network, 4) the Development of Motivation to see value of Learning Organization Development of Primary School Network, 4) the Establishment of document and Handbook for implementation, 5) the Establishment of Plan for developing the Learning Organization of Primary School Network, 6) the Application of Plan for developing the Learning Organization into practice, 7) the Learning in Person, Team, and Organization Levels of Primary School Network, 8) the Sharing in learning, expressing one's opinion as well as solution guidelines, and recommendations, 9) the Summarization of lessons and Reflection of the implementation of Primary School Network, 10) the Discussions and Conclusions of findings, and 11) the Evaluation of implementation.

- The outcomes of Model consisted of 11 items : 1) the Learning Organization Level was known, 2) the School Staffs in Network obtained knowledge and comprehension in precise objective, 3) the School Staffs in Network viewed the importance of development for Learning Organization of Primary School Network, 4) the Implementation Handbook, 5) the Plan for developing the Learning Organization, 6) the School Staffs in Network obtained knowledge and comprehension in work practice, 7) the School Staffs in Network obtained Learning in Personal, Team, and Organization Levels, 8) the School Staffs in Network obtained positive interaction and Learning Network, 9) the Learning Organization, 10) the Satisfaction of School Staffs in Network, and 11) the Learning Organization Model of Primary School Network, was obtained.

b. The findings of Handbook Establishment in using the Model for developing the Learning Organization of Primary School Network, under jurisdiction of the Office of Basic Education Commission consisted of 5 Parts as follows:

- Part 1: Introduction consisted of Principle and Rational, Objective, Goal, and Definition.

- Part 2: the Basic Knowledge of Learning Organization in Primary School Network consisted of the Background of Learning Organization Approach, Network and Aspect of Learning Organization in Primary School Network.

- Part 3: the Learning Organization Model of Primary School Network consisted of the Aspect and Approach of Model, the Model and Technique of Implementation, the Model Structure, the Details of Activities, the Implementation Guidelines, the Learning Source/Worksheet, and the Evaluation.

- Part 4: the Model Usage consisted of the Phase 1; the readiness preparation in Learning Organization of Network, Phase 2; the development of Learning Organization Model of the Network, Phase 3 ; the Stepping into Success in Learning Organization of Network.

- Part 5: the Measurement and Evaluation of Implementation consisted of the Evaluation Form of Satisfaction in Learning Organization of Network, the Posttest, and the Satisfaction Evaluation Form.

3) The Usage of developed Model for Learning Organization Development for developing the Primary School Network, under jurisdiction of the Office of Basic Education Commissions, found that:

a. The learning network evaluation findings of primary school network among administrators and teachers were "high" level in overall for the pre-development which average score for every aspect was 3.64 while the post-development among administrators and teachers were "highest" level in overall which the average score for every aspect was 4.56 . The achievement evaluations were as follows: 
- The Person Level: were the persons of learning, loved to learn continuously, kept pace with changes, were Transformational Leaders, were responsible, used the Media and Technology for work development as well as Systematic Thinking, the findings of evaluation in success, was in "The Highest" level.

- Team in Network Level, Learning together in Team, had shared vision, worked in Team, shared with each other, and collaborated in constructing the new body of knowledge, the finding of evaluation in group success was in "The Highest" level.

- The Network Level, learned in the whole organization, created the Learning Network, included the Learning Culture in Network, the Climate enhanced the Learning, and the Data were systematically stored, the findings of evaluation were in "The Highest" level.

b. The findings in testing the Learning Organization of Primary School Network, under jurisdiction of The Office of Basic Education Commission, the pretest score was 16.64 out of 30 full score, or $55.46 \%$, and the posttest score was 24.67 out of 30 full score, or $82.23 \%$. It showed that the administrators and teachers in Primary School Network had their posttest score in higher level than the pretest score, and every one of them could pass the criterion $80 \%$.

c. The findings of Participants' Satisfaction in Model Development for Learning Organization of Primary School Network, under jurisdiction of The Office of Basic Education Commissions, in overall of every aspect, were in "The Highest" level.

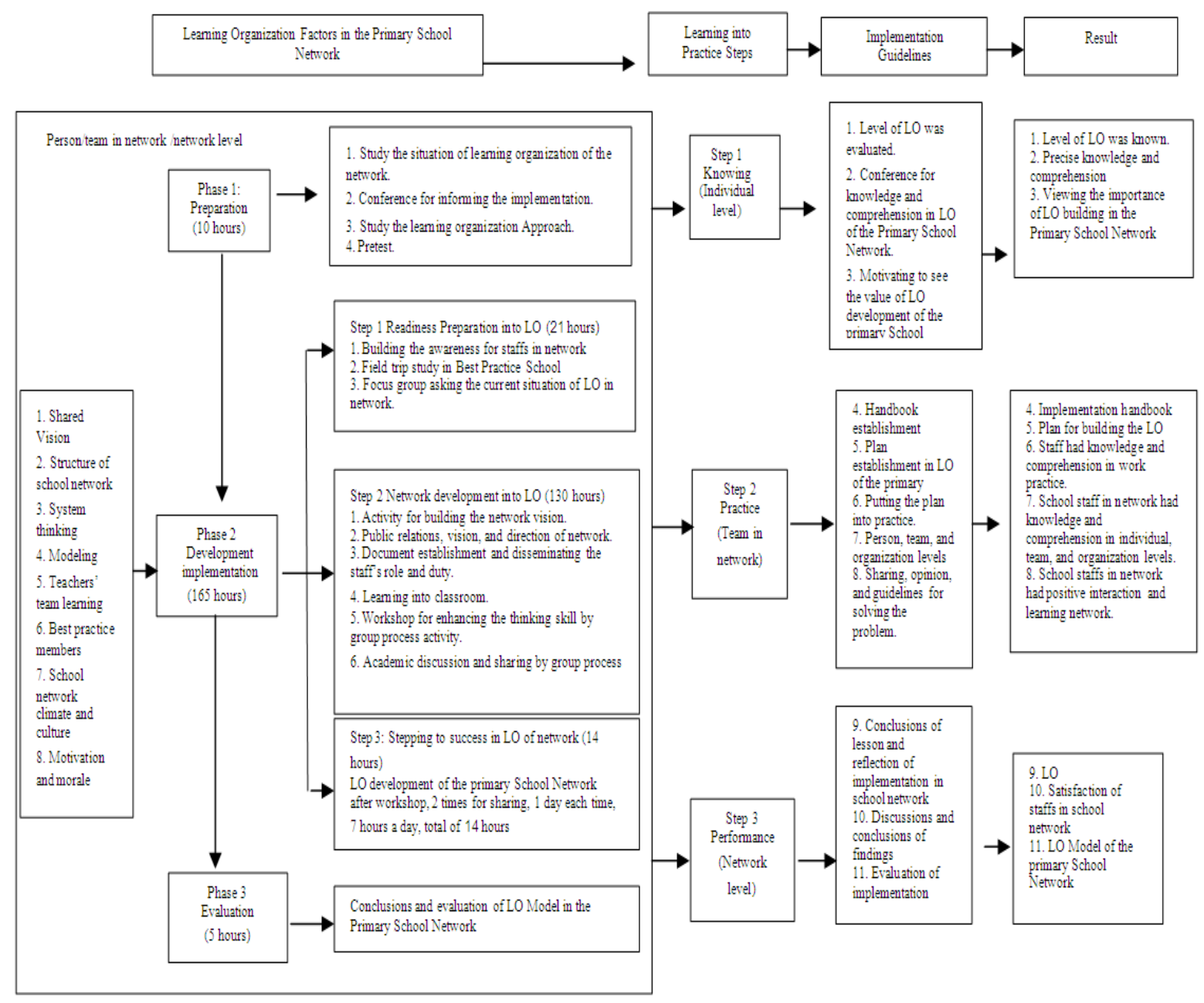

Figure 1. Model of learning organization development of primary school network 


\section{Discussions}

According to the research conclusions, there were interesting issues being discussed as follows:

1) The current situation and problem of Learning Organization of Primary School Network, under jurisdiction of The Office of Basic Education Commission, the overall current situation was in "Moderate" level. Considering each aspect, found that there were 2 aspects in "Low" level, and 6 aspects in "Moderate" level. The overall problem of Learning Organization of Primary School was in "High" level. Considering each aspect, it was in "High" level as well. The research findings would be due to there was congruent between Theoretical Framework and Empirical Data. There were aspects affecting directly the of Learning Organization of Primary School Network, in the following aspects: the Shared Vision, the Structure of School Network, the Systematic Thinking, the Modeling in School, the Teachers' Team Learning, the Best Practice Member, the Climate and Culture of School Network, and the Motivation and Morale Development.

It was supported by research findings of Sanrattana (2002) in "Management Factor and Learning Organization in Primary School, under jurisdiction of The National Primary Education Commission," in the following issues: 1) the level of development in management factor and Learning Organization, 2) the comparison of level in development among the small sized, medium sized, and large sized schools, 3) the relationship of studied variables, 4) the factors affecting the Learning Organization, and 5) the Structure of Causal Relationship between Management Factor, and Learning Organization. The research findings found that: 1) the Primary Schools under jurisdiction of The Office of National Education Commission, The Educational Service Area 9, the little number of schools obtained the development in low criterion of "High" level whereas the development of management factor was in "High" level, 2) the comparative study, found that the there were only 3 cases of Small Sized School obtained development in lower level than the other sized schools at significant level including: the development of school effectiveness which was lower than the Large Sized School, the development of self development, communication, and Transformational Leader which were lower than the Medium Sized School, 3) the relationship among management factors was in "High" level in positive direction, 4) the relationship between management factors, and Learning Organization, was in "Moderate" level, and 5) the path analysis.

It was supported by research findings of Boonsri (2009) in "Learning Organization of Extended School, under jurisdiction of The Office of Nongkai Educational Service Area 2," found that the Learning Organization of Extended School, was in "Moderate" level. Considering the first 3 orders of the highest level of average value, they were: the Shared Vision, the Development of Professional Organization, and the Motivation and Morale Development. The recommendations of guidelines for Learning Organization, found that the schools should collaborate in determining the Vision for specifying the management framework, they should be responsible in decentralization in power and duty, they should provide sufficient budget, they should promote the teachers to solve the problem by conducting classroom research, they should hold regular conference for sharing with each other, they should develop climate in searching for different learning sources, and consider the meritorious fairly.

2) The developed Model of Learning Organization in Primary School Network, under jurisdiction of The Basic Education Commission, consisted of the aspects of model as follows: 1) the aspect of Learning Organization of Primary School Network included 8 aspects and 3 Phases: Phase 1; the Preparation, Phase 2; the Development Implementation, including the Step 1, the readiness preparation in Learning Organization of Network, consisted of 3 activities. Step 2: the development of Learning Organization Model of the Network, consisted of 12 activities, and Step 3, the Stepping into Success in Learning Organization of Network, and Phase 3, the Evaluation, 2) the step of Learning into Practice consisted of Step 1; Creation of Wisdom (person level), Step 2; the Practice (team level), and Step 3; the Performance Measurement (organization level), 3) the Guidelines for Implementation consisted of 1 activities, 4) the outcome of Model consisted of 11 items: the duration of development included 180 hours or approximately 5 weeks. The Model as well as Technique administered various methods for constructing the intensive knowledge, comprehension, and learning skill so that the persons attending development would be able to use for Continuous Self Development. These applied methods for implementing the Model Development consisted of:(1 the Training, (2the Self-Study, (3the Field Trip Study, and (4the Real Practice. For development implementation, 3 steps in developmental processes were specified as follows: 1) The Wisdom Creation, 2) the Practice, and 3) the Performance Assessment. In addition, the Handbook consisted of 5 Parts. Part 1: was the Introduction, Part 2: was the Basic Knowledge of Learning Organization in Primary School Network, Part 3, was the Learning Organization Model of Primary School Network, Part 4, were the Model Usage, and Part 5, was the Measurement and Evaluation of Implementation.

It was supported by research findings of Chanpo (2003) in "Learning Organization Model in Catholic Vocational School of Thailand, found that: 1) the overall situation of factors affecting Learning Organization in Catholic 
Vocational School of Thailand, based on school administrators" opinion found that it was in "High" level, based on teachers' opinion found that it was in "Moderate" level. 2) The level of Learning Organization in Catholic Vocational School of Thailand, based on school administrators and teachers' opinion found that it was in "High" level. 3) The causal relationship of factors affecting Learning Organization in Catholic Vocational School of Thailand, found that the causal relationship of Model in factors affecting the Learning Organization in Catholic Vocational School of Thailand, which was congruent with empirical data.

It was also supported by research findings of Ausiriponrit (2004) in "Development of Indicator in Learning Organization of Basic Schools in Sothern Provinces," found that the variable as major factors affecting the Learning Organization of Basic Schools in Sothern Provinces consisted of 5 major factors as follows: the Organization factor, the Leadership factor, the Learning factor, the Knowledge Management factor, and the Technology factor. All of 5 major factors as Variables had to be practiced through all of 13 sub-factors, and 62 indicators of Learning Organization.

It was congruent with research findings of Koonpleum (2005) in "Development of Learning Organization Model in Private Universities of Thailand," found that the appropriate Model of Learning Organization with Private Universities of Thailand, based on the experts' approach found that the important issues which caused 5 principles based on Senge's Approach consisted of: Principle 1; the Knowledgeable Self included the development of motivation, the wish to learn as well as the ability to change the tension into motivation for performance development. Principle 2; the Development of Mind Mapping including the listening skill as well as the openness to accept the others' opinion, and the usage of various sources of knowledge as data for decision making. Principle 3; the Shared Vision included the officers had to clearly understand the Organizational Vision, and accept that the Organizational Success was every staff's responsibility. Principle 4; the Team Learning included the Development and Promotion of Team Work System as well as Creation of Team Members' Bond. Principe 5; the Systematic Thinking included the Opinion Sharing among those who worked in the same work place as well as among work places, and the Understanding in Work Priority. For the approach of Private Administrators, found that all of 5 major principles included: Principle 1; the Consciousness and Mind Practice to persist on knowing and learning, and use the realistic data as well as logic every time for analytical thinking and decision making. Principle 2; the Adjustment of Educational System by teaching how to think and analyze by oneself, and use the data from various sources as data for decision making. Principle 3; the Acceptance of the others' competency and Efficient Communication. Principle 4; included the Process and Evaluation of Team Members' Work Practice and Provision of Training process for Team Members. Principle 5; included the Understanding in Work Priority as well as Policy Structural System, and Organizational Work Process. The Design had to be able to transform and correct, and be flexible as well as respond what were affected from both of outside and inside the organization.

It was supported by research findings of Sangsook (2005) in "Learning Organization of Primary School based on Teachers' Perception, under The Office of Khon Kaen Educational Service Area 5," found that the Learning Organization of Primary School based on Teachers' Perception, under The Office of Khon Kaen Educational Service Area 5, was in "High" level. Considering each aspect, found that the aspects with the Highest Level of Practice were: the School Climate and Culture and the Motivation. The second order was the Teacher and Teamwork Development. The Aspect with lowest level of practice, was the School Effectiveness which was in "High" level. According to the study, found that the Primary School Administrators expressed their leadership behavior in overall, in "High" level which there was significant influence on the increased work performance of staffs as well as school.

It was supported by research findings of Buapern (2006) in "The Administrators' Role in School Development for Learning Organization in Naresuan Network Group, under jurisdiction of The Office of Prajeenburi Educational Service Area," the samples of this study were 103 teachers selected by Stratified Sampling from Naresuan Network Group, under jurisdiction of The Office of Prajeenburi Educational Service Area, found that: 1) the Administrators' Role in School Development for Learning Organization in Naresuan Network Group, under jurisdiction of The Office of Prajeenburi Educational Service Area, in overall and each aspect, were in "High" level. 2) The Administrators' Role in School Development for Learning Organization in Naresuan Network Group, under jurisdiction of The Office of Prajeenburi Educational Service Area, in overall and each aspect, there were no significant differences between the administrators with high level of experience, and those with low level of experience. 3) The Administrators' Role in developing the school to be Learning Orgaanization in Naresuan Network Group, under jurisdiction of The Office of Prajeenburi Educational Service Area, in overall and each aspect, there were no significant differences.

It was supported by research findings of Prasertsook (2009) in "Management Behavior in Learning Organization 
of School Administrators, Burapa Civilization Network Group, under jurisdiction of Sakaew Educational Service Area 2, found that: 1) the Management Behavior in Learning Organization of School Administrators, Burapa Civilization Network Group, under jurisdiction of Sakaew Educational Service Area 2, in overall and each aspect, were in "High" level, 2) there were significant differences in Management Behavior in Learning Organization of School Administrators, Burapa Civilization Network Group, under jurisdiction of Sakaew Educational Service Area 2, between the administrators with high level of experience, and those with low level of experience, in overall and each aspect $(p>.05)$ except the Building Shared Vision, there were no significant differences, 3) there were significant differences in Management Behavior in Learning Organization of School Administrators, Burapa Civilization Network Group, under jurisdiction of Sakaew Educational Service Area 2, as classified by school, in overall and each aspect, $(p>.05)$ except the Personal Mastery, the Mental Model , and Building Shared Vision, there were no significant differences.

It was congruent with research findings of Osborne (1998) in "The Learning Organization and Leadership for the College System," found that there were 5 aspects as : follows : the Individual learning, and the Leadership Disciplines including the Personal Mastery, the Mental Models, the Building Shared Vision, the Team Learning, and Systems Thinking which were factors determining the Learning Organization.

It was supported by Hill (2002, p. 48) in "Indicator of Learning Organization," she stated that the Learning Organization was important since the empowerment in learning for organizational staffs was important being started by Learning as a major key of the Learning Organization Approach by studying various research studies, the Cultural Learning Model, the Evaluation, the Cultural Survey of Learning and Flexible Program in Organizational Development. The research methodology was also used in the survey based on research and development method. The analysis and instrument validation was used as framework of Organizational Development. The first important topic as the key, was the Learning Organization Approach including: the Empowerment, the Organizational Culture Learning, and the Learning of Organization by being the Learning Organization. The second order was the Learning of Cultural Model, the Cultural Building, and the Survey of Learning Culture. Then, the findings were discussed in order to find the direction of development as well as evaluate the Learning Organization.

3) The findings of usage in Model of Learning Organization Development for developing the Primary School Network, under jurisdiction of The Office of Basic Education Commission, found that:

a. The findings of evaluation in level of Learning Network of School Administrators and Teachers in Primary School Network, before development, in overall, was in "High" level. The overall average value of every aspect was $=3.64$. After the development, in overall, it was in "The Highest" level. The overall average value of every aspect $=4.56$. The findings of evaluation in success, found that the evaluative findings of success in Individual Level was in "The Highest" level, the evaluative findings of group success in Team in Network Level was in "The Highest" level, and the evaluative findings of group success in Network Level was in "The Highest" level. It was supported by research findings of Rangsansarit (2009) in "Model of Development in Learning Organization in Large Sized School, under The Office of Basic Education Commission" found that: 1) the situation of Learning Organization of Large Sized Secondary School, under jurisdiction of The Office of Basic Education Commission, in overall, was in "High" level, 2) the Model of Learning Organization Development in Large Sized Secondary School, under jurisdiction of The Office of Basic Education Commission, included 7 steps of factors as: the determination of Vision for school to be Learning Organization, the determination of strategy for building the Learning Organization, the determination of precise Planning, the organization of activities aimed to be Learning Organization, the development of Culture for accepting the changes and improving the work continuously, the supervision, monitoring, and disseminating the implementation findings, and recognizing the success by the whole organization, 3) The Propriety and Feasibility of Model for developing the Learning Organization of Large Sized Secondary School, under jurisdiction of The Office of Basic Education Commission, the school administrators and teachers viewed that the Model of Development for Learning Organization of Large Sized Secondary School, under jurisdiction of The Office of Basic Education Commission, had Propriety and Feasibility in "The Highest" level. In addition, the Model of Development for Learning Organization of Large Sized Secondary School, under jurisdiction of The Office of Basic Education Commission, there was positive high relationship with the Learning Organization of Large Sized Secondary School, under jurisdiction of The Office of Basic Education Commission, in all of 12 aspects at .05 significant level.

b. The findings in Testing of Learning Organization of Primary School Network, the school administrators and teachers in Primary School Network, the posttest score was higher than the pretest one. Furthermore, every one passed the criterion as $80 \%$. It was supported by research findings of Wanta (2010) in "Learning Organization in of Schools, under jurisdiction of The Office Meenburi District, Bangkok," found that: 1) Learning Organization 
in of Schools, under jurisdiction of The Office Meenburi District, Bangkok, in overall and each aspect, they were in "High" level, 2) the Learning Organization in of Schools, under jurisdiction of The Office Meenburi District, Bangkok, as classified by teachers' experience, in overall and each aspect, there were significant differences $(\mathrm{p}<$. 05) except the Mental Model, the Building Team Learning, and the Systems Thinking, there were no significant differences. The Primary Schools were Learning organization in higher level than the Extended Schools, 4) the Learning Organization in of Schools, under jurisdiction of The Office Meenburi District, Bangkok, as classified by school size, in overall and each aspect, there were significant differences $(\mathrm{p}<.05)$ except the Building Team Learning, there were no significant differences.

c. The evaluative findings of participants' Satisfaction in the Model for developing the Learning organization of Primary School Network, under jurisdiction of The Basic Education Commission, in overall, every aspect was in "The Highest" level. It was supported by research findings of Setajit (2005) in "Situation of Learning Organization in Basic Schools, under The Office Cholburi Educational Service Area 3," found that the opinion of administrators and teachers on Learning Organization Situation in Basic Schools, under jurisdiction of The Office Cholbunri Educational Service Area 3, in overall of 5 aspects, was in "High" level. Considering each aspect, found that every aspect was in "High" level, ranking in order as follows: The Organizational Modification, the Learning Dynamic of Work Practice, the Empowerment, the Knowledge Management, the Usage of Modern Technology. Comparison of opinion in the administrators and teachers in overall of 5 aspects, there were differences. Considering each aspect, found that the there were differences in 4 aspects as: the Learning Dynamic of Work Practice, the Organizational Modification, the Empowerment, and the Knowledge Management. For the Usage of Modern Technology, there were no differences. Classifying their Educational Degree, and Work Experience, there were no differences. It was supported by research findings of Wankam (2010, pp. 218-219) in "Development of Vocational Competency of Small Sized School Administrators, under jurisdiction of The Office of Basic Education Commission," found that the Satisfaction on Training, was in "The Highest" level. It was also supported by research findings of Kaiser (2000) in "Pattern of Learning Organization: A Case Study, Learning Organization Model," found that the influence of Leadership, Culture, Mission, Strategy, Structure of School Network whereas the implementation of Management, Working Climate, Motivation indicated lower level of Influence than the hypothesis. But, there were variables being unexpected by hypothesis as: the Organizational System without Influence on Learning.

According to the above reasons, the researcher conducted research study in "Development of Learning Organization Model of Primary School Network, under The Office of Basic Education Commission," and was aware of value and viewed that the Model of Development included the Utility, Propriety, Feasibility, and accuracy since it could be used in real situation.

\section{Recommendations}

\subsection{Recommendations from Research Findings}

1) The findings of network development by using the Research and Development, was to develop the whole system of Primary School Network. The researcher could have good findings of implementation which could be seen from the changes in target group network. The precise changes, for example, the school staffs in network knew and understood Vision of network, various techniques of instructional management as student-centered were performed more, there were research report in solving the classroom problem continuously, there were library as well as increased various and sufficient learning sources for ones' need, the innovation media was increasingly used for improving the efficiency of learning management, the individual sharing in person level and team level were performed outside and inside network, the Staffs in network had good morale in their work practice. In addition to these changes, the work management structure of network was adjusted, the staffs were assigned work task appropriately with their knowledge and competency more, every division of stakeholders took part in. Therefore, these research findings were very useful for developing the network to be Learning Organization in being applied further.

2) For Model of Development for Learning Organization of Primary School Network, the research was conducted by Research and Development. Since the researcher as well as co-researchers lived in the research area. So, the problem and limitation of network were known. Besides, the Model of Development could be put into practice in satisfactory outcome. The intensive explanation of Phase 1: the Preparation for Readiness into Learning Organization, Phase 2: the Development of Network into Learning Organization, Phase 3: the Successful Step of Learning Organization in Network precisely. In this study, the significance of process was considered.

3) The School Network should develop understanding for school, every teachers and Educational Staff to have 
awareness that the development in Learning Organization of Primary School Network was to be collaboratively implemented. Furthermore, the Best Practices in Primary School had to be extended further.

\subsection{Recommendations for Future Research}

1) The developed Model of Development in Learning Organization of Primary School Network, under jurisdiction of The Office of Basic Education Commissions, was the Model of Development in Learning Organization focusing on overall development so that the school network would apply the Model of Development in Learning Organization of Primary School Network.

2) The Network Development Technique or all of 3 levels in Staff Development Technique including the Person, Team, and Organization Levels should be studied in order to know the precise guidelines for implementation steps of Research and Development.

3) The other aspects of Model of Learning Organization of Primary School Network, should be studied in order to develop the quality of Network Management.

4) The development in Learning Organization of Primary School Network which used to be developed the same as this development, should be followed up in order to know whether the characteristic of Learning Organization in Person, Team, and Organization Levels still be existed, was it developed from the former one? Or What would be any kind of changes? How? Etc.

\section{Acknowledgments}

I would like to express my sincere thanks to my thesis advisor, Dr. Kowat Tesaputa and Dr. Anan Sri-ampai for their invaluable help and constant encouragement throughout the course of this research. I am most grateful for them teaching and advice, not only the research methodologies but also many other methodologies in life. I would not have achieved this far and this thesis would not have been completed without all the support that I have always received from them.

In addition, I am grateful for Dr. Prayad Ruechakul and others person for suggestions and all their help.

Finally, I most gratefully acknowledge my parents and my friends for all their support throughout the period of this research.

\section{References}

Ausiripnrit, S. (2004). Development of Overall Indicator of Learning Organization of Basic Schools in Southern Provinces (Doctoral thesis in Educational Administration, Srinagarinwirote University, Bangkok, Thailand).

Buapern, P. (2006). The Administrators' Role in developing Schools to be Learning Organization in Naresuan Network Group, the Office of Prajenburi Educational Service Area (Master's thesis in Educational Administration, Burapha University, Bangsaen, Thailand).

Chantarasiri, W. (2008). Development of Core Competency in Administrators from Supportive Line in Public Universities (Doctoral thesis in Educational Administration, Mahasarakham University, Maha Sarakham, Thailand).

Charoenwongsak, K. (2002). Network Management: Major Strategy for Success of Educational Reform. Bangkok: S. Asia Place.

Doolayakasem, U., \& Somwittayapong, O. (2007). Educational System and Community: Framework and Recommendations for Research. Bangkok: The Office of Research Promotion Fund (ORP).

Hill, R. (2002). Studies in Human Resource Development. Retrieved from www.amazon.co.uk/s?ie=UTF8\& searchtype $=$ ss\&index $=$ books-uk\& field-author $=$ Rosemary $\% 20$ Hill\&page $=1-111 \mathrm{k}$

Kaiser, S. M. (2000). Mapping the Learning Organization: Exploring a Model of Organizational Learning (Doctoral dissertation, Louisiana State University, Baton Rouge, LA, USA).

Koonpleum, P. (2005). Development of Learning Organization in Private University of Thailand (Master's Thesis in Educational Administration, Burapha University, Bangsaen, Thailand).

Marquardt, M. J., \& Reynolds, A. (1994). The global learning organization. New York: Irwin. http://dx.doi.org/10.1108/09696470010352990

Ministry of Education. (2003). Handbook for Basic School Management as Juridical Person. Bangkok: The Express Transportation and Organization of Thailand.

Office of Basic Education Commissions. (2011). Guidelines for Putting the Educational Standard into Practice. 
Bangkok: The Agricultural Cooperative Association of Thailand.

Osborne, D. R. (2005). The Learning Organization and Leadership for the College System (Doctoral dissertation, Memorial University of Newfoundland, St. John's, NL, Canada).

Pongpaew, M. (2005). Management Factors facilitating the Learning Organization of None-sa-ad Network Schools, under The Office of Udontani Educational Service Area 2 (Master's thesis in Educational Administration, Khon Kaen University, Khon Kaen, Thailand).

Prasertsook, B. (2009). Management Behavior in Learning Organization of School Administrators in Burapa Civilization Network Group (Master's thesis in Educational Administration, Burapha University, Bangsaen, Thailand).

Sangsook, P. (2005). Learning Organization of Primary School as perceived by Teachers, The Office of Khon Kaen Educational Service Area 5 (Master's thesis in Educational Administration, Khon Kaen University, Khon Kaen, Thailand).

Sanrattana, W., \& Sanrattana, U. (2002). Management Factor and Learning Organization in Primary School, under the Office of National Primary Education Commission, Educational Service Area 9. Bangkok: Tipyawisoot Printing.

Senge, P. M. (1990). The fifth discipline: The art and practice of the learning organization. New York: Doubleday.

Setachit, K. (2005). A Study of Learning Organization State of Schools, under the Office of Cholburi Educational Service Area 3 (Master's thesis in Educational Administration, Udontani Rajabhat University, Udon Thani, Thailand).

Soinam, S. (2004). Development of Learning Organization Model in Secondary Schools (Doctoral thesis in Educational Administration, Khon Kaen University, Khon Kaen, Thailand).

Wankam, W. (2010). Present Satisfaction and Future Need affecting the Work Management Mechanism of The District Education Office. Nakonrachasima: The Office of Development in Education, Religion, and Culture in Educational Area 11.

\section{Copyrights}

Copyright for this article is retained by the author(s), with first publication rights granted to the journal.

This is an open-access article distributed under the terms and conditions of the Creative Commons Attribution license (http://creativecommons.org/licenses/by/3.0/). 